\title{
Principles for a future-oriented education system
}

\section{RACHEL BOLSTAD}

\section{Abstract}

A research project commissioned by the Ministry of Education recently presented NZCER researchers with an opportunity to consider how educational research could contribute to the development of a more future-oriented learning system. Our goal was to synthesise ideas from the " $21^{\text {st }}$ century learning" literature with current knowledge about practice issues and future possibilities for innovation in New Zealand education in order to distil a set of themes or principles which a wide audience of educational stakeholders might be able to engage with. While this approach and the themes we have developed are open to critique, we hope this synthesis might provide a platform for educators, researchers, policymakers, and other stakeholders in education to engage in ongoing discussion about how to develop "next practice" and achieve system change.

\section{Introduction}



ducational theorists have long argued that current schooling approaches are not sufficient to address and support $21^{\mathrm{st}}$ century learning needs (See Egan, 2008; Gilbert, 2005; Kress, 2008; Leadbeater, 2011). However, while there is some consensus amongst theorists about the need for transformative change, there is a considerable gap between their views and current schooling practice, and an even greater gap between these and many everyday ideas about education expressed in the public domain through media reporting and day-to-day educational policy rhetoric (Bolstad, 2012; Roulston, 2006). 
Over-used and under-defined terms such as " $21^{\text {st }}$ century learning” do not necessarily clarify matters. When this phrase first appeared during the latter years of the 20th century, it held connotations of the future and of something "different" from practices of the day. But in 2012, does it provide a strong direction for building different, visionary or futures-oriented ideas and practices? My NZCER colleagues and I consider that " $21^{\text {st }}$ century learning" (we prefer "future-oriented" or "Knowledge Age" learning) is not a fixed or known model or approach that is already out there waiting to be found, described, replicated, and implemented across the system. Rather, it is an emerging cluster of ideas, beliefs, knowledge, theories and practices which have deep roots in contemporary theories about knowledge and learning in the context of the massive economic, social, technological, cultural, and environmental developments of the past 50-100 years (Delors, 1998; Kress, 2008; Leadbeater, 2006; Rychen \& Salganik, 2003). Some aspects of these ideas and practices may be visible in some schools and classrooms; others exist only in isolated pockets, and many more are barely visible yet (Bolstad \& Gilbert, 2012).

“ $21^{\text {st }}$ century learning” is linked in many people's minds with the new affordances of information and communication technologies (ICT). While ICTs have the potential to transform how we learn and teach, the kinds of shifts advocated by future-oriented educational theorists go much deeper, and new technologies are only one part of this picture. To enable genuinely transformative changes in education, we along with other future-oriented theorists see the need to address at least two key challenges. The first challenge is to engage a very wide group of people - including educators and the general public - in reconsidering some of the fundamental ideas that underpin current practice, and how well these ideas fit with today's learning needs. Leadbeater (2011, p. 6) suggests that "a new consensus needs to be forged about the kind of learning we should aspire to provide”, a consensus that parents, children and teachers and policymakers can all buy into. However, even if such a consensus can be reached, it is not easy to get from where we are today to where we aspire to be tomorrow. The second challenge is to support all the players in the 
system - from teachers and learners through to families, communities, and educational policy leaders - to engage in the work of redesigning or retrofitting educational approaches and systems to match new understandings of what kinds of learning are needed to succeed and flourish in the $21^{\text {st }}$ century world.

Both of these challenges place new demands on people at every layer of the education system to become more proficient at reflecting on current practices and thinking and working collaboratively in order to build something new. This is as true for teachers, school leaders, and communities as it is for those responsible for shaping educational policy and infrastructure at the highest levels. New Zealand's participation in the Global Educational Leaders Programme (GELP) is illustrative of this. The initiative aims to "support education system leaders with their personal development and transformational leadership as they work to transform education at local, national and global levels". "GELP's guiding principles mirror the kinds of approaches that it is argued school leaders and teachers need to undertake, including the need to work together to develop the change agenda and practices, develop "next practice" and collaborative problem solving, and develop new capabilities while implementing and achieving change.

To support the work of the New Zealand GELP delegates, in 2011 the Ministry of Education commissioned NZCER to undertake a piece of research to develop a vision of "what future learning should look like for New Zealand students”. This presented an opportunity to critically reflect on the contributions of research knowledge and research processes to the work of building a future-oriented learning system (Bolstad, 2011, 2012). As argued above, research into current practice - even that which is considered "best practice" within current frameworks - cannot provide sufficient knowledge to tell us what education could or should be like in the future, nor can it provide proven models for how to address system-level challenges for innovation and transformation. Rather than working towards a picture of "best practice", future-oriented research could be thought of as

See www.cisco.com/web/about/citizenship/socio-economic/docs/gelp_broch.pdf 
working towards the development of a view of "desirable possibilities". It is not about predicting the future, but using research knowledge and processes to support continuous thinking and conversations that can help to create a future that is built around an informed consensus about what is needed, and why.

As educational researchers, how ought we to respond to educational policy leaders' requests for research "to document examples of future focused practice and identify the conditions supporting teaching and learning approaches that enable students to develop the skills, competencies, knowledge and understanding required to participate in, and contribute to, our national and global future"? (Ministry of Education, 2011, p. 4). We believe there is an inherent oxymoron in the notion that research can identify and document examples of the future in today's practice. However, the commissioning of this work presented an opportunity to make use of and build from - the massive body of theoretical and empirical research knowledge that already exists as part of the " $21^{\text {st }}$ century learning” literature (Bolstad \& Gilbert, 2012) and link this to current knowledge about practice issues and future possibilities for innovation in New Zealand education. With a fixed contract budget and a short timeframe ${ }^{2}$, we considered how to generate a research product that would be useful for the policymakers who commissioned it, as well as for a wider audience of educational stakeholders who often look to research to provide guidance about how to “do" $21^{\text {st }}$ century education. We wanted to build from existing work, particularly NZCER school-based research over the past ten years, and use this to identify and to frame the collection of a small amount of new data from schools that believed they were engaging in future-oriented or " $21^{\text {st }}$ century" learning and teaching approaches.

Our goal was to distil a set of themes or principles which a wide audience of educational stakeholders might be able to engage with as the beginning point for conversations about how to achieve a system change. It is important to note here that most of the ideas presented in

2 Interim findings were required within three months in time for the GELP meeting, with the final report required three months after that. 
our synthesis are not new. They have been around for a very long time and are well supported and practised by many teachers. However, our education systems and practices are often set up in ways that do not support these principles to operate in practice, and most of us still have difficulty imagining exactly what it might look like to build educational approaches and systems that deeply reflect these ideas. The challenge here is how to achieve a system shift that creates a more coherent educational ecology that can support what is already known about good learning, can accommodate new knowledge about learning and, importantly, is adaptive to new purposes for learning in a changing world. While our approach and the themes we have developed are open to critique, we hope this synthesis of themes can provide a platform for educators, researchers, policymakers, and other stakeholders in education to engage in ongoing discussion about how to develop "next practice” and achieve system change. We are also interested in other educational researchers' responses to the open question as to the role our community can or should take in response to requests for research-based guidance to support efforts towards more "future-oriented" education.

\section{Methodology}

Our methodology involved three phases, all completed in the period July to December 2011. In phase 1, we synthesised findings across approximately ten years' worth of NZCER studies of innovative schooling practices, and integrated these with themes from the international and New Zealand future-oriented education literature to develop a set of key principles that seem to underpin approaches to learning and teaching that reflect future-oriented educational thinking.

In phase 2 we invited New Zealand schools (teachers and principals) to submit short written accounts of their innovative/21st century/future-focused practices, the ideas and intentions that underpin these practices, perceived issues and challenges, and the 
influences on their thinking about the future of learning. ${ }^{3}$ The 29 submissions received were analysed in relation to the emergent principles for future-oriented learning. We particularly looked for examples that suggested teachers, school leaders, and schools were developing innovative and reflective approaches to practice that might provide engaging examples and insights for other educators.

In phase 3 we collected further data to develop a more in-depth picture of some of the practices described in the written submissions from phase 2. The intention in this phase was to dig underneath the practices to investigate the ideas, intentions, and conditions that underpin the practices, how they are experienced and understood by teachers, learners, and school leaders and the challenges/issues for sustaining and expanding these practices within the current system. Data collection in this phase comprised group teleconference interviews with 18 teachers and school leaders from 15 schools. ${ }^{4}$ Finally, two researchers made one-day case study visits to two schools, selected because, based on their contributions in telephone interviews, it appeared that particularly interesting or innovative practices were occurring in their schools at a whole-school level.

\section{Six emerging principles for a future-oriented education system}

\section{Theme 1: Personalising learning}

Personalising learning was briefly a focus for the Ministry of Education under the Labour government (Ministry of Education, 2006), but Bevan-Brown, McGee, Ward, and MacIntyre (2011) argue that the concept is not yet widely implemented or understood across the sector and that there is a need for specific and ongoing advocacy for personalising learning by the Ministry of Education. Personalising learning calls for reversing the "logic" of education systems so that the system is built around the learner, rather than the learner being required to fit with the system (Green, Facer, \& Rudd, 2005, p. 3).

3 The call for submissions was advertised in the Education Gazette and other channels including NZCER's and the Ministry of Education's electronic newsletters.

4 All those who submitted written accounts in phase 1 were invited to participate in the teleconference calls. 
The idea of personalising learning challenges us to think about how to deploy the resources for learning (teachers, time, spaces, technology) more flexibly to meet learners' needs. It also requires us to think about the new resources that may be needed, beyond those traditionally thought of as part of the schooling system, and how best to support learners' access to those resources.

Today's schools can personalise learning-to an extent-if they are committed to this idea. Contributions from our research participants tended to show an orientation towards personalisation.

One of the key platforms of our belief is to really "understand who our learners are" - we refer to this as "personalising the learning journey for our students" ... we are aiming to break the model of "one size fits all” as we know it actually fits no-one (Area School principal).

However, certain constraints at the system level can impact the extent to which learning can be personalised. We are not yet seeing the kinds of "deep personalisation" argued for by future-focused educationalists in which "users" and "professionals" work together to shape public services that address users' needs, values and aspirations. Leadbeater (2006) argues that children, parents, families, and communities are an "under-utilised resource" in the current education system and suggests that a personalised learning approach could particularly benefit families and communities who have disengaged from education or dropped out of the system, thinking that education and learning are not relevant, not rewarding or simply "not for them". In deep personalisation, learners, and the communities that support them, would have a far greater role - and also far greater responsibilities - for designing solutions from the ground up. The goal is not simply to find better ways to raise everyone's "achievement" to an identical level or standard, but rather to support every person to develop their full potential.

Research undertaken in a variety of New Zealand schools highlights a range of opportunities and tensions for personalising learning in practice. These include difficulties in understanding how learners can be genuinely engaged in shaping their own learning. Various studies (For example, Boyd et al., 2005; Boyd \& Watson, 
2006; Cowie \& Hipkins, 2009; Hipkins, Roberts, \& Bolstad, 2007) indicate subtle but important differences between schools and classrooms where students are genuinely involved in co-constructing meanings and practices associated with their learning, and schools in which teachers or students may use personalising learning language but scratching below the surface, teaching and curriculum practices are still largely "business as usual". In deep expressions of practice, students' learning activities and the curriculum/knowledge content they engage with are shaped in ways that reflect the input and interests of students, as well as what teachers know to be important knowledge. Learners who have had the time, support and opportunities to have input into shaping their learning tend to be better able to describe in their own words what they have come to learn about their strengths, weaknesses, motivations and interests as learners, and how these relates to other contexts of their lives, including their ideas about how they see themselves in the future. In shallow expressions of practice, the curriculum content is still determined by the teacher, and students' input is limited to more shallow choices about which activity(ies) they will undertake to master this knowledge determined by the teacher.

Personalising learning may involve supporting students to learn through authentic, relevant, real-world contexts, where students' interests, aptitudes and the issues and opportunities within their own communities can form the basis for learning. We have researched many initiatives in which students, both primary- and secondary-aged, learn through projects involving real-world contexts, often solving a problem or generating something new in collaboration with other people in their communities (See, for example: Bolstad, Cowie, \& Eames, 2003; Bolstad, Roberts, \& McDowall, 2010; Boyd et al., 2005; Boyd \& Watson, 2006) In deep expressions of practice, students are involved in the key aspects of decision making, and can fully experience the messiness of a real-world project, complete with the unexpected changes in direction, opportunities and challenges that can arise. However, sustaining community-linked real-world learning opportunities often requires time for new partnerships and relationships to form between schools and other people/groups, and teachers and learners need to become comfortable in new roles so that 
learners have more agency and ownership of the direction and outcomes of their learning work.

\section{Theme 2: Equity, diversity and inclusivity}

Current educational policy typically concentrates on the issues of diversity, equity, and inclusivity in relation to particular groupings of learners and communities for whom educational success has lagged behind that of other learners and communities. There is a recognition that these learners' and communities' needs have not been well met by the education system in the past, and a major goal of the current education system is to address the needs of "diverse" learners in order to raise overall achievement levels and reduce disparity. In New Zealand, this has been a particular policy focus for Māori and Pasifika learners and those with special learning needs.

We believe there is a need to support educational policy leaders and educators to develop new ways of thinking about equity and diversity. Achieving equity is not just about addressing the underachievement or disengagement of particular groupings of students and communities and bringing everyone closer to a single normative standard of what counts as success. This is particularly important given the arguments that currently accepted markers of success in education probably do not adequately reflect the kinds of learning that are needed for the demands of the 21st century. "Diversity" needs to be recognised as a strength for a future-oriented learning system, something to be actively fostered. This calls for greater engagement of learners, family/whānau and communities in co-shaping education to address their needs, strengths, interests and aspirations, while also ensuring that all students - no matter where they are from or where their learning happens - have opportunities to develop and succeed according to the high-level educational aspirations set for, and agreed to, by New Zealanders as a whole. However, policies and programmes designed to support greater community engagement to support students' learning success may come with embedded ideas about how and why schools need to engage particular communities, and about what they wanted to gain from "partnership" with these communities. This can be problematic for two main reasons. First, it may limit the opportunity for those 
communities to define the ways in which they would wish to be involved or the types of outcomes they might want a partnership to achieve. Second, there may be unexamined assumptions which may not be shared by all involved. It can take time to work through these assumptions and enable genuine negotiation of goals and approaches that work for the particular learners and communities involved. Even schools that are committed to meeting the needs of all their students and wish to engage with their school community in order to achieve this may still experience considerable challenges in forging these connections. Schools may be hampered by a lack of clarity about the purposes of community engagement and what should ultimately be achieved. (Bull, 2011; Hipkins, Cowie, Boyd, Keown, \& McGee, 2011). However, in some schools we have encountered educators who look to the strengths of the community as a resource to support learning aspirations for students, as in the quote below from a school in a largely Māori community that was integrating ideas about "enterprising" education with an understanding of the aspirations and needs of students and the community in which the school was situated.

[We are] looking for solutions to issues within our school and local community-looking at our own internal strengths - what's pumping in our blood. (Year 10 agriculture teacher, cited in Bolstad et al., 2010, p. 156)

Another idea that appears in the " $21^{\text {st }}$ century education" literature is the notion that 21st century citizens need to be educated for diversity - in both the "people" sense and the "knowledge/ideas" sense. The changing global environment requires people to engage and be able to work-with people from cultural, religious and/or linguistic backgrounds or world views that are very different from their own. Alongside this, doubts about the ability of existing paradigms to solve current social, environmental and economic challenges mean that a future-focused education system must provide learners with the ability to think between, outside and beyond current paradigms - that is, the ability to work with a diversity of ideas. Our research synthesis suggests that schools are currently seeing "diversity" mainly in terms of finding ways to help learners from nondominant social groups improve their engagement and success in 
education. It is more difficult to find research evidence about schools engaging with the second set of ideas - education for diversity (of people and ideas/knowledge).

Theme 3: A curriculum that uses knowledge to develop learning capacity

Gilbert (2005) argues that one of the biggest challenges for education in the 21st century is that our ideas about curriculum are currently underpinned by at least two quite different epistemologies regarding knowledge. The first view is the "traditional" idea of knowledge as content, concepts and skills selected from the disciplines to form the "subjects" or "learning areas" of the school curriculum. From this point of view, the learner's job is to absorb and assimilate that knowledge into their mind and demonstrate how well they have done this through various means of assessment. It is assumed that this knowledge will be stored up for later use during the learner's life.

The second conception of knowledge is associated with the Knowledge Age/“21st century” literature. In this view, knowledge is seen as something that does things, as being more energy-like than matter-like, more like a verb than a noun. Knowledge, in the Knowledge Age, involves creating and using new knowledge to solve problems and find solutions to challenges as they arise. The Knowledge Age literature argues that reproducing existing knowledge can no longer be education's core goal, because (a) it is no longer possible to determine exactly which knowledge people will need to store up in order to use it in their lives after school, and (b) the "storing up for future use" model of knowledge is no longer useful or sufficient for thinking about how knowledge is developed and used in the 21st century. Instead, the focus needs to be on equipping people to do things with knowledge, to use knowledge in inventive ways, in new contexts and combinations. There is ample research evidence to show that even young children can engage in knowledge-generating learning, shaping new ideas and acting on their environment given the appropriate resources and learning supports.

What this means for the school curriculum is a shift in what is "foregrounded". Instead of simply assuming these capacities will be 
developed through engagement with disciplinary knowledge (the traditional view), there is a shift to focusing on the development of everyone's capabilities to work with knowledge. From this point of view, disciplinary knowledge should be seen, not as an end in itself, but as a context within which students' learning capacity can be developed. While the use of the term "learning areas" in The New Zealand Curriculum (NZC) (Ministry of Education, 2007) document signals this, it is clear that this has not changed underlying thinking for many educators. It seems clear that the work of building a 21st century education system must involve supporting educators - and the public - to understand the paradigm shift in the meaning of such apparently common-sense terms as "knowledge" and "learning", and how this might change the way curriculum is interpreted and applied in learning and teaching experiences.

Because practice in today's schools is underpinned by a mixture of ideas about knowledge and learning, it is not surprising that schools may pick up some ideas (e.g., the goal of "lifelong learning") while still retaining older ideas about knowledge and curriculum that don't really support this goal. Many of these older ideas are reinforced by structures and cultures within schooling, as well as at the system level. This means that potentially transformative 21st century learning ideas are often reinterpreted within more familiar/traditional frames, and as a result curriculum and teaching practices change relatively little. ${ }^{5}$ However, research shows that some schools can develop more coherent approaches that open the opportunity for more significant shifts. One way this can occur is when high-level organising ideas support people to see curriculum, teaching, and learning through a new lens. "Unifying" ideas from the front half of the New Zealand Curriculum, including key competencies, education for sustainability, and education for enterprise, has helped some schools to find coherence across ideas, creating opportunities for deeper shifts in learning, curriculum, school organisation, and school-community relationships (Bolstad et al., 2003; Bolstad et al., 2010; Boyd et al., 2005; Boyd and Watson, 2006).

5 This mirrors the "deep" versus "shallow" expressions of personalising learning discussed above. 
Theme 4: "Changing the script": Rethinking learners' and teachers' roles

Twenty-first century ideas about knowledge and learning demand shifts in the traditional roles of learners and teachers. If the purpose of schools is not to transmit knowledge, then teachers' roles must be reconceived. Similarly, if the learner's main job is no longer to absorb and store up knowledge to use in the future, then learners' roles and responsibilities also need to be reconceived. These ideas are often shorthanded with phrases such as "student-centred pedagogies" or "student voice", alluding to the need to engage learners (and their interests, experiences, and knowledge) in many decisions about their learning. However, the idea of sharing power with learners can be met with resistance, particularly if this is interpreted as an "anything goes" approach in which learners are given complete freedom to set the direction for their learning. The challenge is to move past seeing learning in terms of being "student-centred" or "teacher-driven", and instead to think about how learners and teachers would work together in a "knowledge-building" learning environment. This is not about teachers ceding all the power and responsibility to students, or students and teachers being "equal” as learners. Rather, it is about structuring roles and relationships in ways that draw on the strengths and knowledge of each in order to best support learning.

The idea of teachers as facilitators of learning has traction amongst many educators, even if the shifts they aspire to have yet to be realised in practice. Research in primary schools that were early adopters of ideas around the key competencies (Boyd \& Watson, 2006) found that exploring the KCs was moving schools away from content-focused topic learning. Increasing emphasis was being placed on students developing learning dispositions and a wider range of skills and competencies, and the schools were moving further towards pedagogies of co-construction. Professional development (PD) experiences were important for teachers to be comfortable with this. The recent Curriculum Implementation Exploratory Studies (CIES) found that NZC was a catalyst for conversations about the role of teachers, learners, and the community in setting directions and roles (Cowie \& Hipkins, 2009; Hipkins et al., 2011). Many schools in the 
studies were attempting to move from fixed content-driven models of curriculum delivery. The focus on collaborative knowledge building was supported by prior and current PD initiatives, including ICT PD Clusters, Assess to Learn, Principals’ Professional Leadership Groups, the Ariki project and Literacy Professional Development Programme. In several schools, new thinking about the intent of the curriculum was characterised as moving the content focus from "what" to include the "how" and "why" of learning. In one area school this change was described as a "paradigm shift" in teachers' understanding, with a related shift from teaching contexts, to teaching for the development of big ideas and important concepts.

Theme 5: A culture of continuous learning for teachers and educational leaders

All of the principles discussed above suggest that teachers, school leaders, educational policy leaders, and other adults supporting young people's learning need particular attributes and capabilities that enable them to work effectively towards a future-oriented learning system. Some of the approaches advocated for 21st century learning - and the ideas that underpin them - may differ from what today's teachers, school leaders and educational policy leaders experienced in their own school learning. Teachers and school leaders may resist adapting current approaches if they don't see the need for change, or if they aren't convinced that adapting current approaches is possible, let alone likely to lead to better student outcomes.

This means that education systems must be designed to incorporate what is known about adult learning and cognitive development as well as what is known about young people's learning and development. This has implications for thinking about professional learning approaches and structures for teachers and school leaders. Are adults in the education system able to access the kinds of learning supports that they need in order to be the best leaders for a future-oriented learning system? There is a substantial challenge in providing organisational structures and systems that can adequately support educators' ongoing professional learning needs (Resnick, 2010). Several of the teachers and school leaders who made submissions about their future-focused practices for this research wanted to have 
contact with each other for the purposes of continuing and extending the "leading edge" of their own thinking and practices. Some expressed a feeling of "loneliness" as individuals or schools doing things differently. They were keen to be involved in networks and relationships that would enable their ideas to be pushed further by others who have been thinking along similar lines. Some already had these, but others didn't-and wanted them. Several schools had established networks with other "future-focused" and innovative schools/educators both in New Zealand and internationally for this purpose.

The Inservice Teacher Education Practice (INSTEP) project represented one example of an effort to promote a strategic and coherent focus across the system in the area of inservice teacher learning. In an evaluation of INSTEP (Sankar, 2009, p. 3), participants commended the project's goals of "bringing together practitioners from across the sector to work collaboratively to examine, inquire, and build knowledge." INSTEP provided opportunities for inservice teacher educators (ISTEs) to examine their own theories of learning, deprivatise practices they had evolved over years, and trial alternative approaches to develop deeper understandings of how to engage teachers and school leaders in professional learning. The evaluators reported that the adoption of a research and development approach over three years had contributed significantly to the knowledge base around this area, and this was seen as an acknowledgement of the importance of inservice teacher education as a lever for change.

Collaborations between schools, policy makers, and researchers have also proved useful in supporting emerging 21st century practice and enabling system-level learning. For example, clusters of schools in two curriculum innovation research projects worked together to build practice through a series of workshops which included sharing of school practices as well as input from policy and research. These learning communities were a valued source of ideas and challenges for school leaders, lead teachers, researchers and policy makers (Boyd et al., 2005, Boyd \& Watson, 2006). 
Theme 6: New kinds of partnerships and relationships: Schools no longer siloed from the community

As argued at the outset of this article, education will not have traction to shift towards more 21st century approaches if this shift is not supported by the wider community. Public education is a collective good in which everyone has a stake. To be legitimate it must build our collective social and economic capacity and meet individual needs immediate (and/or perceived) and future. To do both requires community understanding of, support for, and contribution to what is being attempted. This "buy-in" could be achieved by engaging community members in authentic educational activities that draw on the resources of the wider community, particularly as schools simply do not have the resources to provide "in house" all of the very different kinds of expertise needed to develop 21st century learning experiences for their students. Educators will need to be able to collaborate with other people who can provide specific kinds of expertise, knowledge, or access to learning opportunities in community contexts.

Some schools are already engaging with people and groups from the wider community to support learning in innovative ways. If this work is to be scaled up, it needs systemic support and clear linkages to the future-oriented learning ideas. Educators and other partners from the wider community need support to work in the spaces between their different areas of expertise, to talk, and to listen to each other-across professional and/or cultural boundaries.

\section{Conclusion}

This synthesis of themes is partial, and we welcome critique from our peers in the educational research community regarding how useful this collection of themes is or could be for promoting discussion within and outside the educational community about how to reshape education to better meet " $21^{\text {st }}$ century" learning needs.

New Zealand research suggests to us that the six themes discussed above already exist in current practice - albeit in various stages of development. Our synthesis suggests that what is needed is not more effort focused on the parts of this system (as we have seen in the past 
with the fostering of, for example, personalising learning, or community engagement), but strategies designed to put these ideas together. Picking out one or two of these ideas in isolation will not be enough. What we need is to join them all up in a way that is driven by a coherent set of shared ideas about the future of schooling and its purpose and role in building New Zealand's future. Research can already tell us much about how things are, and future-oriented research can help us to consider how things could be. The next step is to use this knowledge to support enriched conversations and development work amongst all players and stakeholders in the learning system about how this might be achieved.

\section{References}

Bevan-Brown, J., McGee, A., Ward, A., \& MacIntyre, L. (2011). Personalising learning: A passing fad or a cornerstone of education? New Zealand Journal of Educational Studies, 46(2), 75-88.

Bolstad, R. (2011). Taking a "future focus" in education-what does it mean? An NZCER working paper from the Future-Focused Issues in Education (FFI) project. Wellington: New Zealand Council for Educational Research.

Bolstad, R. (2012) What role might research play in supporting future-oriented community engagement with education? A working paper from the Changing Minds project. Wellington: New Zealand Council for Educational Research

Bolstad, R., \& Gilbert, J., with McDowall, S., Bull, A., Boyd, S., and Hipkins, R. (2012). Supporting future-oriented learning \& teaching: A New Zealand perspective. Wellington: Ministry of Education.

Bolstad, R., Cowie, B., \& Eames, C. (2003). Environmental education in New Zealand schools: Research into current practice and future possibilities. Wellington: Ministry of Education.

Bolstad, R., Roberts, S., \& McDowall, S. (2010). Education and enterprise: Learning at the interface. Final report from the Regional Education for Enterprise Clusters Evaluation. Report prepared for the Ministry of Education, New Zealand Trade and Enterprise, and the Tindall Foundation. Wellington: Ministry of Education.

Boyd, S., \& Watson, V. (2006). Shifting the frame: Exploring integration of the key competencies at six normal schools. Wellington: New Zealand Council for Educational Research.

Boyd, S., Bolstad, R., Cameron, M., Ferral, H., Hipkins, R., McDowall, S., et al. (2005). Planning and managing change: Messages from the Curriculum Innovation Projects. Wellington: Ministry of Education. 
Bull, A. (2011). Families and Communities Engagement in Education. Project 2-Notions of partnership. Working Paper No. 1. Wellington: New Zealand Council for Educational Research.

Cowie, B., \& Hipkins, R. (2009). Curriculum Implementation Exploratory Studies. Wellington: Ministry of Education.

Delors, J. (Ed.). (1998). Education for the twenty-first century. Paris: United Nations Educational, Scientific and Cultural Organisation.

Egan, K. (2008). The future of schooling: Reimagining our schools from the ground up. New Haven: Yale University Press.

Frame, B., \& Brown, J. (2008). Developing post-normal technologies for sustainability. Ecological Economics, 65(2), 225-241.

Gilbert, J. (2005). Catching the knowledge wave? The knowledge society and the future of education. Wellington: NZCER Press.

Green, H., Facer, K., Rudd, T., with Dillon, P., \& Humphreys, P. (2005). Personalisation and digital technologies. UK: Futurelab.

Hipkins, R., Cowie, B., Boyd, S., Keown, P., \& McGee, C. (2011). Curriculum Implementation Exploratory Studies 2. Final report. Wellington: Ministry of Education.

Hipkins, R., Roberts, J., \& Bolstad, R. (2007). Key competencies: The journey begins. Wellington: NZCER Press.

Kress, G. (2008). Meaning and learning in a world of instability and multiplicity. Studies in Philosophy and Education, 27, 253-266.

Leadbeater, C. (2011). Rethinking innovation in education: Opening up the debate. Melbourne: Centre for Strategic Innovation.

Leadbeater. C. (2006). The future of public services: Personalised learning. In Personalising education (pp. 101-114). Paris: OECD.

Ministry of Education. (2006). Let's talk about: Personalising learning. Wellington: Learning Media.

Ministry of Education. (2007). The New Zealand Curriculum. Wellington: Learning Media.

Ministry of Education. (2011). Supporting $21^{\text {st }}$ century teaching and learning for New Zealand students. Unpublished RFP, Ministry of Education.

Resnick, L. (2010). Nested learning systems for the thinking curriculum. Educational Researcher, 39(3), 183-197.

Roulston, D. (2006). Education policy change, newspapers and public opinion in New Zealand, 1988-1999. New Zealand Journal of Educational Studies, 41(2), 145-162.

Rychen, D., \& Salganik, L. (Eds.). (2003). Key competencies for a successful life and a well-functioning society. Cambridge, MA: Hogrefe \& Huber.

Sankar, M. (2009). Evaluation of the Inservice Teacher Education Practice Project (INSTEP). Wellington: Ministry of Education. 


\section{The author}

Rachel Bolstad is a senior researcher at the New Zealand Council for Educational Research. Her research interests include the future of education, school-based curriculum development and innovation, and the changing nature of educational research in the knowledge age.

Email: rachel.bolstad@nzcer.org.nz

\section{Acknowledgements}

This work was developed as a research project funded by the Ministry of Education. We are grateful to the Ministry of Education team who provided feedback on the work, particularly Jo MacDonald, Marg McLeod, and Ro Parsons. I would like to thank the two reviewers who provided useful critique on this manuscript. I would also like to thank my colleagues at NZCER whose work was drawn on extensively in developing and elaborating on the futureoriented themes, particularly Jane Gilbert, Ally Bull, Sue McDowall, Sally Boyd, and Rose Hipkins. 